\title{
Letter to the Editor on "Visitation restrictions: is it right and how do we support families in the NICU during COVID 19?"
}

\author{
D. V. Venkatesh Murthy ${ }^{1} \cdot$ N. Karthik Nagesh (i) $^{1}$
}

Received: 6 October 2020 / Revised: 19 November 2020 / Accepted: 22 January 2021 / Published online: 15 February 2021

(c) The Author(s), under exclusive licence to Springer Nature America, Inc. 2021

\section{To the Editor:}

Sir, We read with interest your article regarding visitation restriction in neonatal ICUs (NICUs) and the need for family support during the COVID-19 pandemic [1]. In developing countries like India, severe community transmission of COVID-19 has now led to constantly evolving issues like the need for further visitation restriction in the NICU [2]. There are however, differences and confusion in policies for viral testing, advice on personal protective equipment use and family/maternal visitation rights to NICU all over the world with no common guidelines yet. Some units allow mothers to visit unrestricted after initial screening for COVID-19 by RTPCR whereas others have only a questionnaire survey regarding symptoms to be filled before visitation [3]. Also the policy on "Kangaroo care" by the parent inspite of its overwhelming benefits is unclear and is not uniformly being practiced during the pandemic due to fears of transmission [4].

We are of the opinion that parent visitation especially of the mother has potentially significant impact on parental attachment and wellbeing with good effects on the infant's physical and mental health [5]. Family centered care also support parents to understand the importance of interaction with their infant which can improve their growth and development [6]. Kangaroo care in the NICU has potential benefits including improved temperature regulation, improved sleep wake cycles and augmented growth [7]. Hence, it should not be denied to the sick and extreme preterms in the NICU during the pandemic. But full visitation potentially can lead to overcrowding, non-maintenance of social distancing, breach in masking, and other NICU protocols for preventing COVID-19 transmission with possible consequences of spread to health care personnel, other parents visiting the

N. Karthik Nagesh

drkarthiknagesh@gmail.com

1 Dept of Neonatology and NICUs, Manipal Hospital, Bangalore, India
NICU or worse, postpartum transmission to the neonate closely in contact with the parent. This is especially true for asymptomatic parents with COVID-19 infection.

We feel this issue has not been clarified in your article and hence need clarity whether visitors including the mother and father of babies admitted for a long time periods in the NICU need to be periodically screened by throat swab RTPCR /RAT for COVID-19 in order to allow their unrestricted visitation in the NICU. This is in view of newer data emerging which suggest significant community transmission in developing countries [2]. Parents have also of late, been insisting for routine screening for COVID-19 for themselves due to fear of contracting nosocomial infection via hospital visits. Some neonatal units apart from screening healthcare workers have started screening parents also who seek this voluntarily. We, hence wonder if this policy of screening needs to be extended for parents regularly visiting in the NICU as well! We request your clarification on this issue so that this policy can be followed in units allowing free access for parents to visit babies in NICU.

\section{Compliance with ethical standards}

Conflict of interest The authors declare no competing interests.

Publisher's note Springer Nature remains neutral with regard to jurisdictional claims in published maps and institutional affiliations.

\section{References}

1. Murray PD, Swanson JR. Visitation restrictions: is it right and how do we support families in the NICU during COVID-19? J Perinatol. 2020;40:1576-81.

2. Murhekar MV, Bhatnagar T, Selvaraj S, Rade K, Saravanakumar V, Vivian Thangaraj JW, et al. Prevalance of SARS-CoV infection in India: findings from national serosurvey. Indian $\mathrm{J}$ Med Res. 2020;152:48-60.

3. Ashley DM, White RD, Velaquez A, et al. Impact of restrictions on parental presence in neonatal intensive care units related to coronavirus disease 2019. J Perinatol. 2020;40:36-46. 
4. Kangaroo Mother Care foundation, Joint Advocacy Statement from NHM, Chattisgarh, UNICEF Chattisgarh. NEWSLETTER. 2020;XIV:28-30. http://www.kmcfoundationindia.org/KMCNew sletterApril-June2020.pdf.

5. Tscherning C, Sizun J, Kuhn P. Promoting attachment between parents and neonates despite the COVID 19 pandemic. Acta Paediatr. 2020. https://doi.org/10.1111/apa.15455.
6. Ding X, Zhu L, Zhang R, Wang L, Wang TT, Latour JM. Effects of family centred care intervention on preterm infants and parents in NICU; A systematic review and meta-analysis. Aust Crit Care. 2019;32:63-75.

7. Campbell-Yeo ML, Discher TC, Benoit BL, Johnston CC. Understanding kangaroo care and its benefits to preterm infants. Pediatr Health Med Ther. 2015;6:15-32. 